\title{
Social Media and its Impact on Decision Making for Trip
}

\author{
Dr. Irma SHYLE \\ Polytechnic University of Tirana, \\ Department of Production and Management \\ irmitash@yahoo.com \\ Assoc. Prof. Dr Vjollca HYSI (PANAJOTI) \\ University of Tirana, Faculty of Economy, \\ Head of Marketing Department \\ viollcapanajoti@feut.edu.al
}

\begin{abstract}
Social networks are not a new phenomenon of the human community. Social communication tools represent a revolution in terms of the possibility of publicity for enterprises. In this way mechanisms of social networks have not only changed the instruments, but also the communication. Social media is not focused exclusively on the development platform of promotion and communication, but also in the implementation of services to create new business opportunities and career. Professional groups present in networks are often closed and specifically dedicated towards specific groups in order to achieve defined objectives and set by direction of the company that benefit from these platforms. Social communications tools represent a revolution in terms of publicity opportunities for enterprises. Social media is becoming the key marketing tool for organizations who manage tourist destinations, in this way having a major impact on tourism markets. The role which social media is playing in various aspects of life is becoming increasingly every day, especially in areas such as social interaction and cultural and educational aspects of our lives. Social media are becoming important tools in marketing management for companies of tourist destinations, having a major impact on tourism markets. The arrival of new technologies such as social media have made it possible to change the way consumers seek information on their buying decisions. Ease of use, flexibility and interactivity offered by these social sites makes it easy for customers to get information that after all generate sales. These interactive web pages that have the status of social communities encourage consumers to interact with the community, strengthening prospects of customers. This will be resulted in customers who visit the community more often to get the desired information (Poon, A. 1993). With advices or knowledge that they get from the community they build the perception of destination and are used for making decisions by consumers. The purpose of this paper is to highlight the use of social media and the impact of social media in the decision making to travel by consumers choosing Albanian.
\end{abstract}

Key words: social media, internet, decision making, tourism, consumers

\section{Social media and consumers attitudes}

To consider social media as a marketing communication tool must understand every aspect of them. Kaplan and Haenlein (2010) define social media as a grouping on the Internet based on the applications that have built ideological and technological foundations of Web and allow the creation and exchange of content created by user (Sinclair and Vogus 2011). However, there are some basic characteristics necessary for a website to be called the site into a social network. Pages should contain user profiles, content, a way that allows users to have contact with each other to communicate, to post comments on sites to each other and to join in virtual groups based on common interests (Gross and Acquisti, 2005; Ellison, Steinfield \& Lampe, 2007; Lenhart \& Madden, 2007).

So, social media is the environment in which social networks have taken place and have changed the way that consumers gather the information you need to make decisions. It is vital for retailers to be aware of the factors that influence the attitudes and motivations of consumers because consumers are changing the concept that for the markets (Heinonen 
2011). As a result, current research, show which aspects of social media websites are affecting consumer attitudes and motives.

One of the most visible phenomena of new media is that it has grown and has established new forms of social interaction. People spend more than a quarter of the time on the Internet including communication activities (eg, emails and social networks), a time equal to the total time spent for fun (Hill \& Morgan, 2011). Consumer behavior studies show that individuals give greater consideration to the information shared on the Internet, spend more time on websites that offer of third parties assessments (Huang et al. 2009) and other studies show that this information can directly affect the buying decision (Awad et al 2006; Weiss et al, 2008). Actually, many of the benefits reported for the use of new media are increasing reputation and the predictability that dealing directly with aspects of its social interaction (Kollock 1999; Arthur et al 2006).

As noted by Steuer (1992) quoted by Ronald P. Hill and Nora Moran (2011) differently from watching TV or listening to the radio, new media interactivity allows customers not simply remain passive receiver of the message but to become active . Interactive is one of the definitions of characteristics of new media technology, providing greater access to information, as well as supporting the growth of user control and engagement with social media content (Fiore et al. 2005). Interactivity depends on the context. In a context of social networks on the Internet, interactive refers to a user therefore concentrated connection with computers, messages or other users focusing on experimental aspect of networking.

People have communicated through writing, photos and videos about years and years and just social media on the Internet provides a medium to continue this trade. Safko \& Brake (2009) even argue that it is possible about any one to have participated in social media without admitting it p.sh reading: a blog, the messages of another member of a community or watching a video on Youtube.

In social media anyone can create and distribute free content that can be viewed by millions of people (Zarella 2010). Consequently Safko \& Brake (2009) explain that the difference of social media is that basically all have the ability to influence, for example, a citizen becoming a witness of an event and its publication on the Internet or marketing of a product by the recommending to others. In the new world of social media and the rapid growth of many different channels of social media, it is almost impossible to not have people talking about the company or their product. On this basis it is necessary to understand social media by each business in the modern world. Social networking sites are intended to unite people together and provide a place where conversations can be made between people and there is no limited space and time (Safko \& Brake, 2009). Social networks are based on human interaction making online conversations. In social networks people relate to their colleagues helping each other, transfer and receive information.

Facebook is the largest social network in the world that connects us to people you know (Pearlman \& Abram, 2010). Facebook is a social utility that helps you communicate with your friends, family and friends (Mashable 2011). Facebook is free and open to everyone from students to professionals, teenagers to grandparents, ordinary people and celebrities even though it was originally designed only to Harvard students in the United States (Pearlman \& Abram, 2010). According to Vander Veer (2010) Facebook combines the best blogging, forums and online groups, distributing pictures and much more. Diversity of Facebook provides opportunities for various businesses and service popularity makes it one of the most important tools for social media marketing purposes. The company develops technologies that facilitate the sharing of information through its digital mapping and social relationship of people (Mashable 2011).

\section{The use of social media and its potential impact on travel decisions}

Some researchers reviewed at how consumers use social media when planning a trip, where most of them came to the conclusion that different types of social media are playing an important role in planning the trip, but not as the only source and not at each stage of the travel planning process (Gretzel \& Yoo 2008; Cox et al, 2009; O'Connor, 2008).

Gretzel \& Yoo (2008) examined the use and impact of online travel websites (TripAdvisor), where their findings indicate changes in the use of these reviews in various stages of travel planning and travel aspects. They argue that the critics are already used in the idea stage, and not only in critical phases that determine the election.

Cox et al. (2009) found in his research that the different sites of social media are considered useful but in different levels, eg, photos and locations posted by real travelers were argued as the most useful, followed with little difference from the reviews travel and lastly social networking sites, as only $25 \%$ of respondents considered them useful. Thus, $51 \%$ of online buyers who participated in the survey stated that social media helped them to limit their choices, $23 \%$ argued that social 
media played a role in the confirmation of their choice, while $15 \%$ used it to determine the final choice. However, the impact of social media after the purchase is important among those who have used social media during the travel planning process.

According to the results of a study published by the European Commission on developments in the tourism market in Europe, in terms of resources that are used by tourists to decide where to spend their holidays for 2011, with respondents from 27 European Union countries, shows that $52 \%$ of respondents claim that the recommendations of friends, colleagues or relatives are very important when they make decisions about where to spend the holidays, while 4 in 10 people or $40 \%$ of respondents claim that the websites are very important in the decision to perform holiday. While regarding the study done through interviews in this paper show that $97 \%$ of respondents definitely influenced by the negative comments of their friends in the choice of destination and $3 \%$ of them will never influenced. According to the European Commission report "Attitudes of Europeans Towards Tourism", which takes into account the 27 European Union countries in 2011, 53\% of those who did vacation, used the internet to carry out bookings, so it is a significant percentage compared with the rest of the respondents.

The study was based only on those people who spent at least 4 days holiday and who constituted $60 \%$ of total respondents. Only $23 \%$ of respondents said they planned their vacations addressing tourism travel agencies, followed by $22 \%$ of respondents who stated that they booked their vacation through someone who knew. Similarly, 1 in 5 people or $18 \%$ of respondents performed bookings via telephone, while less than $9 \%$ of respondents stated that bookings performed on-site, as well as through transportation companies with only $4 \%$. Also, the study showed that the higher the education level of the respondents, the more likely was that he / she to had booked holidays through the Internet. At the same time, employees and self-employed, about $63 \%$ more likely to organize their holidays through the internet, than the unemployed or laborers, who usually plan vacations by asking friends or relatives.

\section{Data analysis}

Results for the age of the respondents (graph 1), show that the highest percentage among them, is comprised of 18 to 25 years old with $36 \%$, and a significant part of the age category 26 to 30 years old with a rate of $27 \%$.

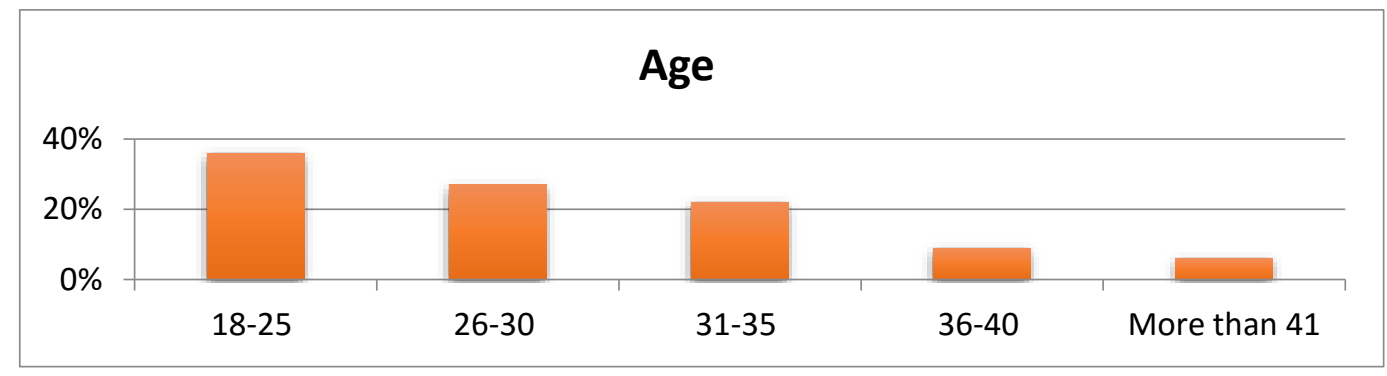

Graph 1. Age

Category with the smallest proportion is over 41 years old age with $6 \%$ and that for the fact that this age is less active in their involvement in social networks. The ratio between men and women is $63 \%$ female and $37 \%$ male (graph 2 ). 


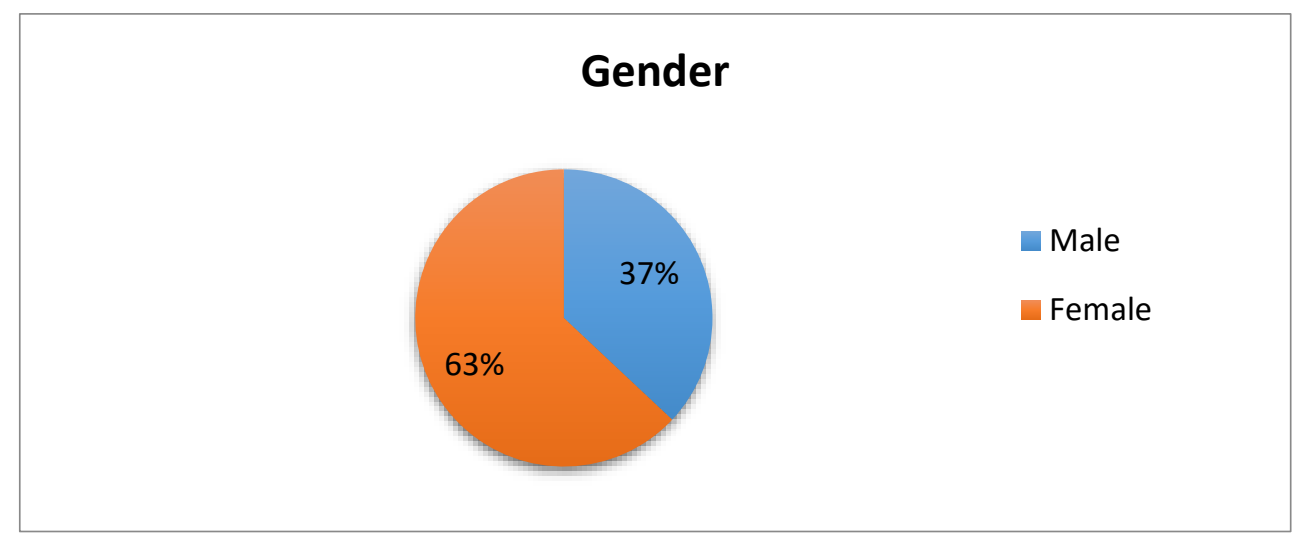

\section{Graph 2.Gender}

$40 \%$ of respondents, traveling on average once a year; $21 \%$ travel on average twice a year; $17 \%$ travel three times a year and $22 \%$ of them travel more than three times a year (graph 3 ).

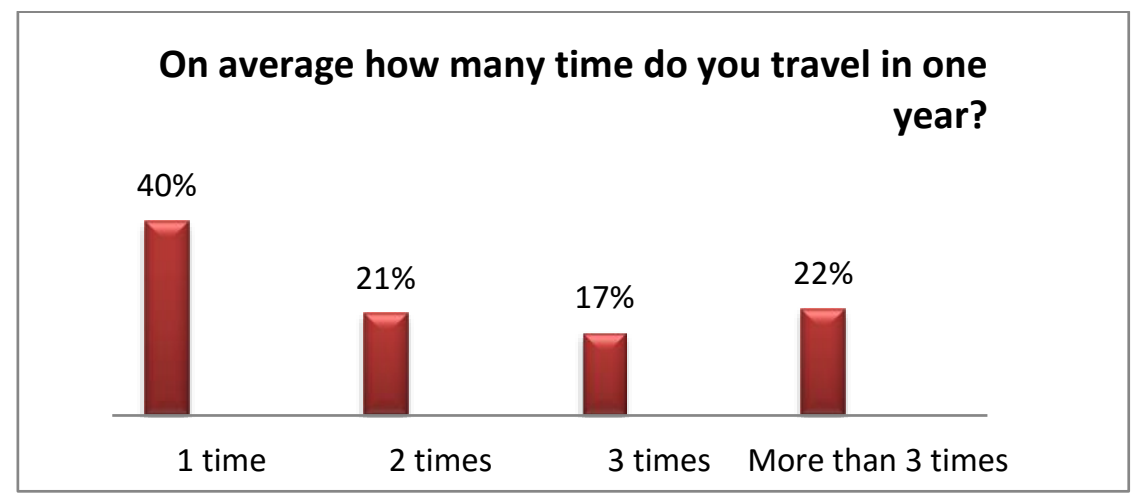

Graph 3. The frequency of travel within the country or abroad

According to data obtained, $91 \%$ of respondents would seek information on social networks when deciding to make a trip and $9 \%$ would not use social networks to be informed (graph 4 ). 


\section{Are you looking for information about tickets, hotels or tourist packages in social networking sites when you plan a trip?}

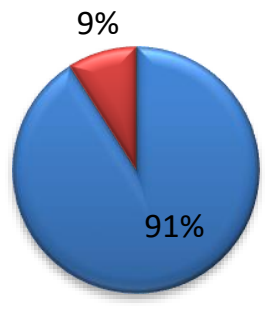

$\square$ Yes

$\square$ No

Graph 4. Search for travel information on social networking sites

In terms of trust that respondents in information obtained through social networks, $21 \%$ of respondents think that this information is not reliable at all, $33 \%$ of them consider this little reliable information, $37 \%$ of respondents think that the information is reliable and a small percentage of $9 \%$ consider this information very reliable (graph 5).

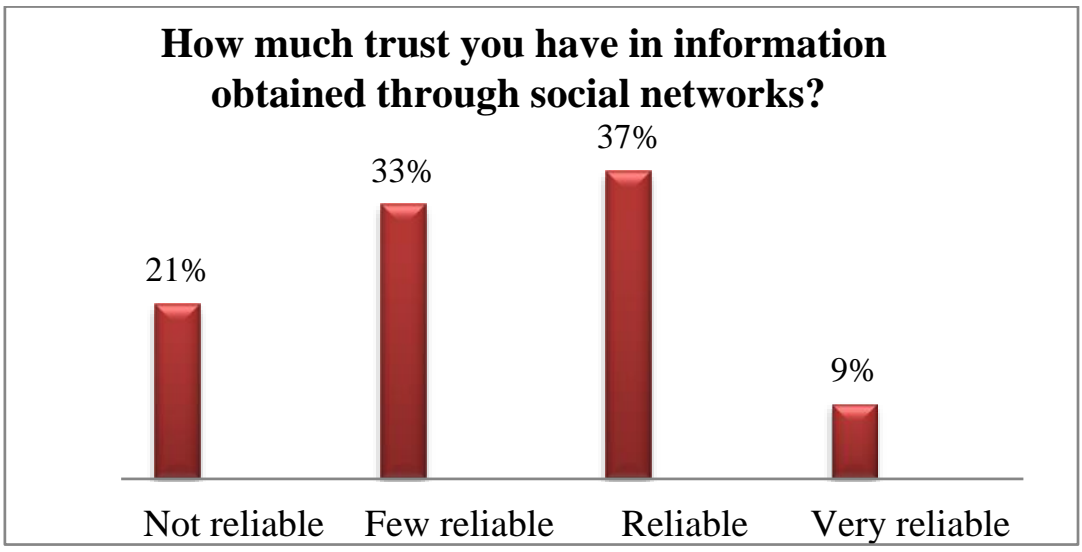

Graph 5. Trust on information obtained through social networks?

From the data provided in graph 6 , it appears that individuals, in relation to travel, have more confidence in conversations they have with friends and less confidence they have in comments in social media.

Table 6. Reliability of sources of information

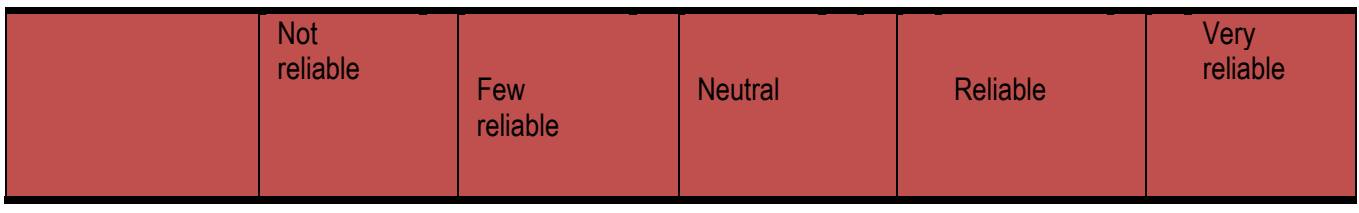




\begin{tabular}{|l|c|c|c|c|c|}
\hline Site of internet & $11 \%$ & $23 \%$ & $30 \%$ & $24 \%$ & $12 \%$ \\
\hline $\begin{array}{l}\text { Comments in the } \\
\text { social media }\end{array}$ & $10 \%$ & $28 \%$ & $31 \%$ & $22 \%$ & $9 \%$ \\
\hline $\begin{array}{l}\text { Conversation } \\
\text { between friends }\end{array}$ & $0 \%$ & $2 \%$ & $17 \%$ & $38 \%$ & $46 \%$ \\
\hline Travel agencies & $7 \%$ & $15 \%$ & $26 \%$ & $39 \%$ & $13 \%$ \\
\hline
\end{tabular}

$97 \%$ of respondents definitely are influenced by the negative comments of their friends in the choice of destination and $3 \%$ of them will not be affected never (graph 7).

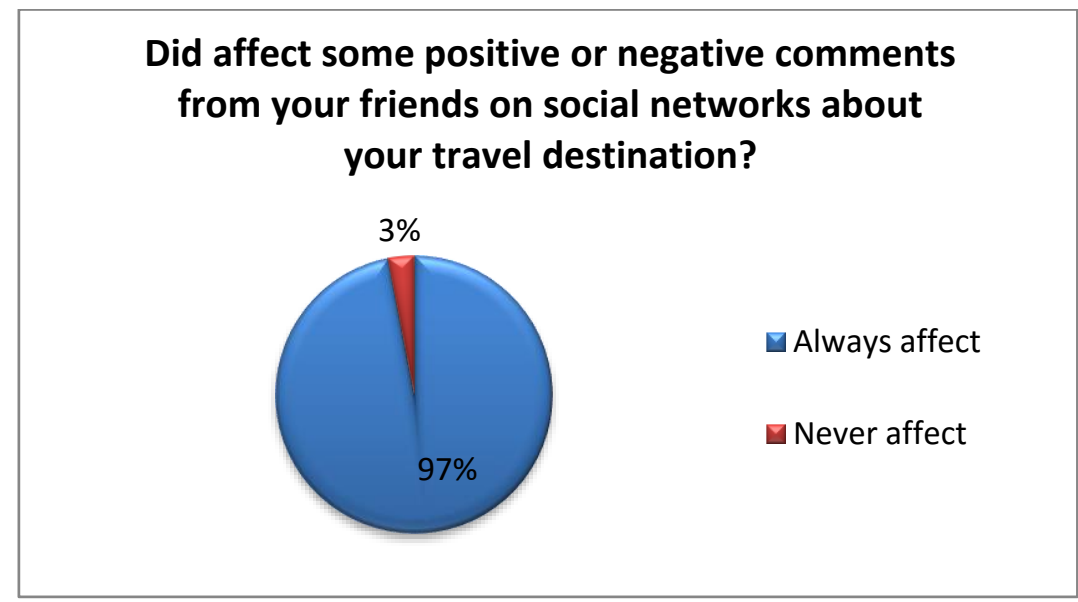

Graph 7. The influence of friends' comments in social networks

From the above graph, $9 \%$ of respondents always click on social networking sites, $23 \%$ click often, $43 \%$ sometimes, $21 \%$ rarely and $6 \%$ do not ever click on these package tours (graph 8 ). 


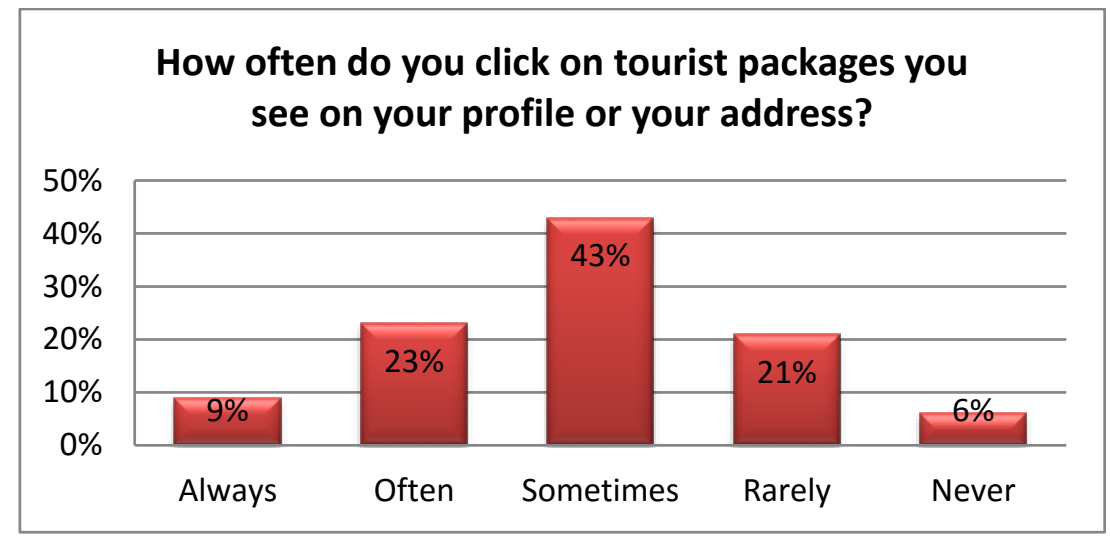

Graph 8. Frequency of clicking on tourist packages

Based on data collected, only $41 \%$ of respondents have taken a trip, because published tourist package has been attracted, but most of them- $59 \%$ is not affected by this reason and undertake trips for other reasons (graph 9)

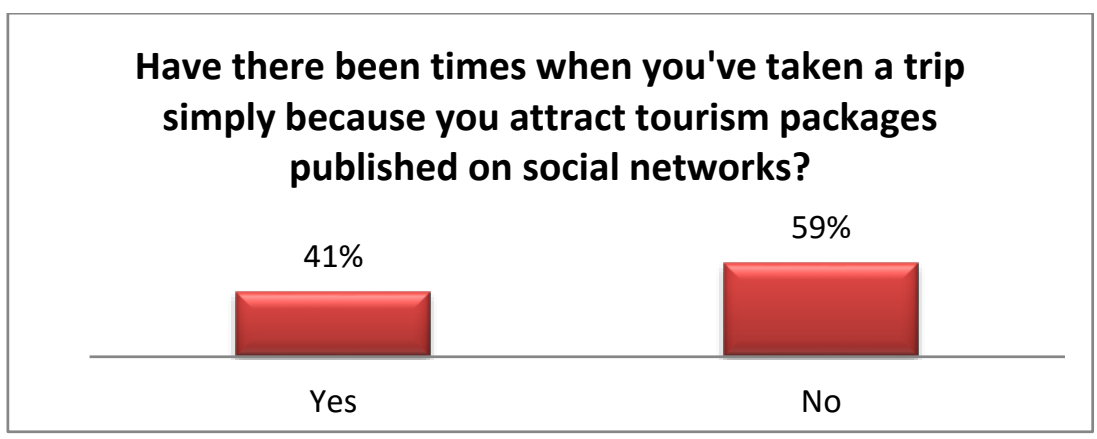

Graph 9. Have taken a trip simply because of attracted tourism packages published on social websites.

By the interviewees $41 \%$ have taken more than twice journey simply because they are attracted tourist packages published on social networking websites, $27 \%$ twice and only one time have experienced $32 \%$ of respondents (graph 10).

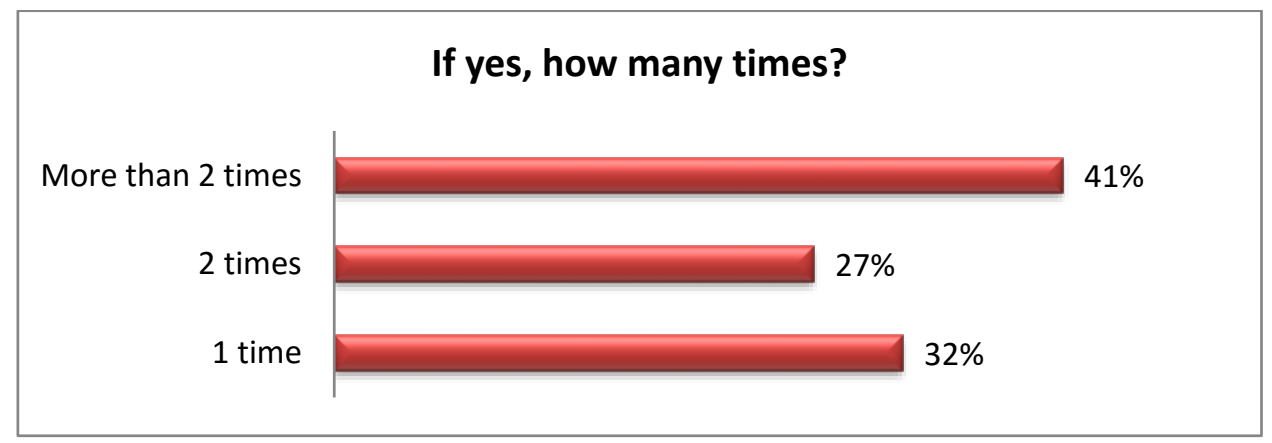

Graph 10. If yes, how many times? 


\section{Conclusions}

Social media brings a series of promotional advantages and it is because social media enables the combination of a variety of elements such as text, video, audio and photos. This combination brings a great advantage in integrated marketing communications. Social media is a new trend but fast growing and therefore it must be managed well.

Social networks such as Facebook, Youtube \& Webpage have gained popularity and trends are showing that consumers more educated and young people have started to be every day more connected with them, thus being part of their everyday life.

Social networks are a good tool to promote because they recognize high use, are reliable, there is interest for the information they provide and have a high monetary cost.

Social media in some way converts customers, ie users of social media, as advertising and promotion channels. Customers can create positive or negative pressure for the company, its products and services, depending on how the company is presented to them. So the image or the perceived quality of consumers, affects opinion or message that they will transmit to others in social media.

\section{References}

[1] Awad, N.f., Dellarocas, C. \& Zhang, X. (2006). "The digital divide of word of mouth. Proceedings of the first Midwest united States Association for Information Systems", Grand Rapids, Ml (May 5-6).

[2] Filho, L. M., and F. B. Tan. (2009). "User-generated content and consumer empowerment in the travel industry: A uses \& gratifications and dual-process conceptualization". Paper 28 presented at the Pacific Asia Conference on Information Systems (PACIS).

[3] Heinonen, K. (2011). Consumer activity in social media: Managerial approaches to consumers' social media behavior. Journal of Consumer Behaviour, 10(6), 356-364. doi:10.1002/cb.376

[4] Hill, P.R., Moran, N. (2011). "Social marketing meets interactive media: lesson for advertising company", International Journal of Advertising, 30(5), pp. 815-838 DOI: 10.2501/IJA-30-5-815-838

[5] Hill, S., Provost, F. \& Volinsky, C. (2006). "Network-Based Marketing: Identify likely adopters via consumer networks", Journal of Statistical Science, vol. 21, no.2, pp .256-276 DOI: 10.1214/088342306000000222

[6] Mangold, W., Faulds, D., 2009. Social media: The new hybrid element of the promotion mix. Business Horizons 52(4), 357-365.

[7] Murugesan, S. 2007. 'Understanding Web 2.0', IT Professional, 9(4): 34-41, July/August

[8] Safko's, Brake's The Social Media Bible (The Social Media Bible: Tactics, Tools, and Strategies for Business Success by Lon Safko and David K. Brake (Paperback - May 4, 2009))

[9] Sinclaire, Jollean K. and Clinton E. Vogus. 2011. "Adoption of social networking sites: an exploratory adaptive structuration perspective for global organizations." Information Technology Management 12: 293-314, DOI 10.1007/s10799-011-0086-5.

[10] Social Media in Travel, Tourism and Hospitality: Theory, Practice and Cases edited by Marianna Sigala, Evangelos Christou, Ulrike Gretzel

[11] Youcheng Wang, Quaehee Yu, Daniel R. Fesenmaier: Defining the virtual tourist community: implications for tourism marketing 